\title{
ANALYTICAL MODELING OF ALGAN/GAN/INGAN HIGH ELECTRON MOBILITY TRANSISTORS (HEMTS) THROUGH POLARIZATION EFFECTS
}

\author{
V. Sandeep \\ Research Scholar, Centre for VLSI Design, Department of Electronics and Communication Engineering, \\ Kalasalingam Academy of Research and Education, Virudhunagar, (India). \\ E-mail: sandeep.vuud404@gmail.com \\ ORCID: https: / / orcid.org/0000-0002-0425-8688
}

J. Gharles Pravin

Associate Professor, Centre for VLSI Design, Department of Electronics and Communication Engineering, Kalasalingam Academy of Research and Education. Virudhunagar (India).

E-mail: charles@klu.ac.in ORCID: https://orcid.org/0000-0002-9009-6274

\section{Citación sugerida:}

Sandeep, V., y Pravin, J. C. (2021). Analytical modeling of AlGaN/GaN/InGaN High Electron Mobility Transistors (HEMTs) through polarization effects. 3C Tecnología. Glosas de innovación aplicadas a la pyme, Edición Especial, (noviembre, 2021), 371-383. https://doi.org/10.17993/3ctecno.2021. specialissue8.371-383 


\section{ABSTRACT}

High Electron Mobility Transistors (HEMTs) are high frequency hetero-junction transistors used for various high-power applications like RF, radiation, space etc. AlGaN/GaN HEMTs form Two-Dimensional Electron Gas (2DEG) when subject to stress between the junction of a wide bandgap and low bandgap material. It is essential to evaluated the charge denstiy induced due to polarization present in the 2DEG area, so the subsequent number of electrons present in the quantum well can be evaluated. The polarization and the sheet carrier density profiles are investigated in the $\mathrm{AlGaN} / \mathrm{GaN}$ hetero-structures with an InGaN back-barrier layer (AlGaN/GaN/InGaN hetero-structure). The impact of InGaN back-barrier on the polarization effects at the interfaces between AlGaN/GaN as well as GaN/InGaN are studied here. An effective 2DEG density is obtained at a peak value of $3.75 \times 1013 \mathrm{~cm}-2$. The graph is interpolated using linear interpolation. The carrier concentration and the density in the 2DEG region has a significantly enhanced value when compared with the conventional $\mathrm{AlGaN} / \mathrm{GaN}$ HEMTs. The sheet carrier concentration of the proposed $\mathrm{AlGaN} / \mathrm{InGaN} / \mathrm{GaN}$ heterostructure attained $24 \%$ increase than the one achieved with the conventional $\mathrm{AlGaN} / \mathrm{GaN}$ structure. The outcomes prove that this device could be potential candidate for microwave and power switching applications.

\section{KEYWORDS}

HEMT, AlGaN, GaN, InGaN, MATLAB, 2DEG, Polarization, Carrier concentration. 


\section{INTRODUCTION}

The group III-V nitride-based semiconductors has been essential materials for electronic device applications that concern high power and high frequency applications. Over the years, several III-V group semiconductors have been employed for these kinds of applications. The Gallium Nitride High Electron Mobility Transistors (HEMTs) due to its unique characteristics have found to be well suited for high power and Radio Frequency applications (Fletcher \& Nirmal, 2017). Various group III-nitrides like Gallium Nitride $(\mathrm{GaN})$, Aluminum Nitride (AlN), and Indium Nitride $(\operatorname{InN})$, are used for the formation of high mobility devices due to their above-mentioned properties such as High breakdown field and high velocity saturation. The bound charge of sheet charge strength of nitride materials on the alloys of $\mathrm{GaN}, \mathrm{InN}$ and $\mathrm{AlN}$ have been given in Foutz et al. (1999).

Due to their capability to handle large power at higher frequencies, the AlGaN/GaN HEMT comes out as a next-generation RF and microwave power amplifier. HEMT is a hetero-structure device. Hetero- structure device generally satisfies the demands of high speed, high power and high frequency. HEMT is widely utilized for applications that suit very high frequencies. One of the main benefits of the HEMT hetero-structure which make it suitable for high-speed applications is the creation of Two-Dimensional Electron Gas (2DEG).

The 2DEG is formed at the junction of the hetero-structure which enhances the electron mobility of the device, which is caused due to the interfacing of wide bandgap (doped) and the low bandgap (undoped) materials. 2DEG happens because of the polarization effects formed in the hetero-junction. Simulated variation and lattice mismatch during formation of the hetero-structure gives rise to polarization. When a doped (wide band-gap) material is grown over an un-doped (narrow band-gap) material, due to difference in their band energies the lattice structure tends to adjust to each other's atomic structures (Ambacher $e t$ al., 2000; Ambacher et al., 1999).

The material properties of $\mathrm{AlGaN}$ make it a viable contender for high-speed applications. The InGaN layer is mainly used for improving the electron mobility present in 2DEG. Disorderly scattering of alloys could be reduced using the InGaN layer and it also helps in improving the concentration of 2DEG in the hetero-junction (Kumar, Arya, \& Ahlawat, 
2013; Bernardini, Fiorentini, \& Vanderbilt, 1997). Due its increasing concentration property and carrier mobility, it is used for high power applications.

The properties evaluated in the $\mathrm{AlGaN} / \mathrm{InGaN} / \mathrm{GaN}$ hetero-structure, which are compared to existing $\mathrm{AlGaN} / \mathrm{GaN}$ structure. The $\mathrm{AlGaN} / \mathrm{GaN}$ has a wurtzite structure. The structure of $\mathrm{AlGaN} / \mathrm{GaN}$ is shown in Figure 2. Strain happening in the top layer causes piezoelectric polarization which could be five times of that happening in conventional $\mathrm{AlGaAs} / \mathrm{GaAs}$ structure which significantly increases the carrier concentration of the interface (Baskaran et al., 2013). In comparison to $\mathrm{AlGaN} / \mathrm{GaN}$, the addition of InGaN layer has higher piezoelectric polarization. The total polarization induced charge density is evaluated by adding both the spontaneous and piezoelectric polarization. By adding a hetero layer in place of the existing one, the tensile and compressive strain gives rise to piezoelectric polarization. The stress depends on the lattice parameter value of $\operatorname{InGaN}(\mathrm{Yu}$ et al., 1997).

Liu et al. (2006) reported an AlGaN/GaN/InGaN/GaN double-heterojunction HEMT (DH-HEMT) with high mobility 2DEG and reduced buffer leakage. The electron mobility obtained in this structure is 30\% higher than in conventional AlGaN/GaN HEMT. Replacement of AlGaN barrier layer in AlGaN/GaN HEMT with the InAlN layer with varying Indium mole fractions is suggested in Kuzmik (2002). The n++GaN/InAlN/AlN/ GaN HEMT by effect of bulk and interface traps is studied in Molnár et al. (2014) using Sentaurus TCAD simulation. Their result depicted the affect in free carrier concentration in the channel by acceptor traps.

Two types of polarization effects exist in the region: piezoelectric polarization and spontaneous polarization. Spontaneous polarization happens due to strong structural defects in the lattice structure whereas the piezoelectric polarization is caused due to mismatch of lattice structures happening in the device when the two hetero materials are grown one over another. This paper concentrates on finding the polarization induced charge density and sheet carrier concentration for the $\mathrm{AlGaN} / \mathrm{InGaN} / \mathrm{GaN}$ hetero-structure which is derived from the self-consistent Poisson and Schrodinger equations. The remaining of the paper is divided into the following sections. Section II depicts the proposed method used. Section III shows the results and discusses the outcomes. Section IV concludes the paper. 


\section{DEVICE STRUCTURE AND MODEL FORMULATION}

The AlGaN/GaN layer could function at higher temperatures and voltages better than other III-V group materials since it has a wide energy bandgap. The AlGaN/GaN/InGaN structure is the proposed model as shown in Figure 1. The sheet carrier concentration in Two-dimensional electron gas (2DEG) region of the AlGaN/GaN/InGaN structure changes with change in polarization induced charge density.

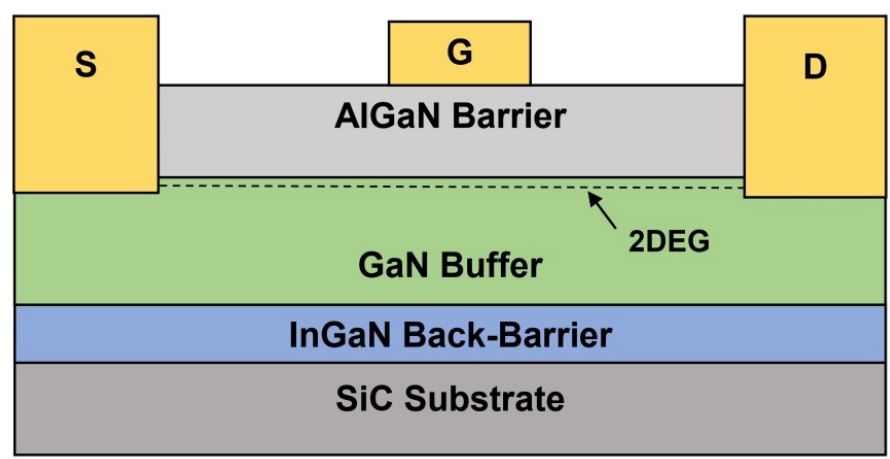

Figure 1. AlGaN/GaN/InGaN Hetero-structure.

Source: own elaboration.

\section{A. Spontaneous polarization}

During zero strain state of the III-V semiconductor, a polarization effect takes place in the equilibrium lattice known as spontaneous polarization. The ionicity of III- $\mathrm{V}$ group covalent bond is much smaller than the ionicity of covalent bond. The spontaneous polarization of $\mathrm{GaN}$ is higher than AlN, due to its dependency on the mole fraction of $\mathrm{Al}$. The spontaneous polarization of the $\mathrm{AlGaN} / \mathrm{GaN} / \mathrm{InGaN}$ is given below as described in Vetury et al. (2001).

$$
\mathrm{P}_{\mathrm{sp}}(\mathrm{x})=(-0.052 \mathrm{x}-0.081) \mathrm{c} / \mathrm{m}^{2}
$$

B. Piezoelectric polarization

The strong iconicity present in the metal- nitrogen covalent bond changes the ideality of the III nitride lattice thus bringing heavy modifications lattice polarization. Strain is a way through which the ideality of the crystal can be changed. Piezoelectric polarization in the structure is caused due to the stress in the lattice. The applied stress changes the ideal lattice parameters by varying $\mathrm{a} 0$ and $\mathrm{c} 0$ in the crystal structure. The strength of polarization varies 
accordingly, by change in lattice parameters a 0 and $\mathrm{c} 0$. The total polarization decreases with increase in $\mathrm{a}_{0} / \mathrm{c}_{0}$ ratio and vice versa.

$$
\mathrm{P}_{\mathrm{PE}}=\mathrm{e}_{33} \varepsilon_{\mathrm{Z}}+\mathrm{e}_{31}\left(\varepsilon_{\mathrm{x}}+\varepsilon_{\mathrm{y}}\right)
$$

The piezoelectric polarization $\mathrm{P}_{\mathrm{PE}}$ depends on the strain along the c axis $\varepsilon_{\mathrm{Z}}$, as well the inplane stress $\varepsilon_{\mathrm{x}}$ and $\boldsymbol{\varepsilon}_{\mathrm{y}}$. Here $\mathrm{e}_{33}$ and $\mathrm{e}_{31}$ are termed piezoelectric coefficients.

The relationship between lattices constant is given as (Kuzmik, 2002):

$$
\frac{\mathrm{C}-\mathrm{C}_{0}}{\mathrm{C}_{0}}=-2 \frac{\mathrm{C}_{13}}{\mathrm{C}_{33}} \frac{\mathrm{a}-\mathrm{a}_{0}}{\mathrm{a}_{0}}
$$

Here $\mathrm{C}_{0}$ is height of the crystal structure; $\mathrm{C}_{33}$ and $\mathrm{C}_{13}$ are elastic constants

Using both the equations the piezoelectric polarization is given as (Vetury et al., 2001):

$$
P_{P E}=2 \frac{a-a_{0}}{a_{0}}\left(e_{31}-e_{33} \frac{C_{13}}{c_{33}}\right)
$$

This piezoelectric polarization is calculated in the c- axis.

\section{Polarization sheet charge}

Polarization effects lead to forming the bound charge density by attracting the bound sheet charge. Positive bound charge leads to negative sheet charge. The total sheet charge due to piezoelectric and spontaneous polarization is caused in both the structures: AlGaN/GaN and AlGaN/GaN/InGaN (Yu et al., 1997).

$$
\frac{\sigma}{\varepsilon_{\mathrm{PE}}}=\mathrm{P}_{\mathrm{PE}}+\mathrm{P}_{\mathrm{sp}}
$$

The relaxation degree and the Aluminum concentration $\mathrm{x}$ is considered for calculating the sheet carrier concentration. The degree of relaxation is calculated as (Vetury et al., 2001):

$$
r(x)=\frac{a(x)-a(A l N)}{a_{0}(x)-a(A I N)}
$$

where $\mathrm{a}$ is the lattice constant.

The increase in relaxation degree leads to a linear increase in sheet charge. Since there causes a maximum piezoelectric polarization in the junction, the strain relaxation could restrict the induced sheet carrier density. 
D. Sheet carrier concentration

The carrier concentration $\mathrm{n}_{\mathrm{s}}(\mathrm{x})$ is formed due to several other factors including total charge density $\sigma(x)$ which is evaluated by

$$
\mathrm{n}_{\mathrm{s}}=\frac{\sigma(\mathrm{x})}{\mathrm{e}}-\left(\frac{\epsilon_{0} \epsilon(\mathrm{x})}{\mathrm{d}_{\text {algan }} \mathrm{e}^{2}}\right)\left[\mathrm{e} \varphi_{\mathrm{b}}(\mathrm{x})+\mathrm{E}_{\mathrm{F}}+\Delta \mathrm{E}_{\mathrm{c}}(\mathrm{x})\right]
$$

Where $\sigma(\mathrm{x}) / \mathrm{e}$ is the polarization induced charge density, $\epsilon$ is the Dielectric constant of material, e is the charge, $\mathbf{e}_{\mathrm{b}}(\mathrm{x})$ is the height of Schottky barrier, $\mathrm{E}_{\mathrm{F}}(\mathrm{x})$ is the Fermi level energy and $\Delta \mathrm{E}_{\mathrm{C}}$ is the offset for conduction band.

\section{RESULTS AND DISCUSSION}

Based on the equations obtained for Polarization sheet charge earlier, analytical modeling was carried out in the $\mathrm{AlGaN} / \mathrm{GaN} / \mathrm{InGaN}$ structure for finding the sheet carrier concentration.

Mathematical modeling was also performed for calculating the charge density and electron concentration for the sheet carrier for the conventional AlGaN/GaN HEMT as given in Ambacher et al. (2000).

The analytically modeled equations for the charge density and sheet carrier concentrations were evaluated for the proposed $\mathrm{AlGaN} / \mathrm{GaN} / \mathrm{InGaN}$ hetero-structure using the MATLAB software. It was later compared with the existing AlGaN/GaN HEMT.

The final results show that the proposed $\mathrm{AlGaN} / \mathrm{GaN} / \mathrm{InGaN}$ hetero-structure displayed improved performances in terms of both charge density as well as sheet carrier concentration than the AlGaN/GaN HEMT.

\subsection{SIMULATION RESULT OF POLARIZATION SHEET CHARGE}

The sheet charge density is first found out for the $\mathrm{AlGaN} / \mathrm{GaN} / \mathrm{InGaN}$ hetero-structure which was solved self-consistently using the Poisson and Schrodinger equations. 


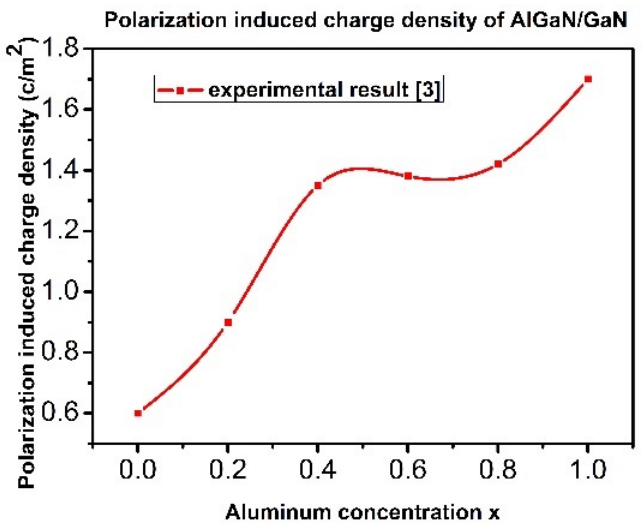

Figure 2. Polarization induced charge density of AIGaN/GaN Hetero-structure. Source: own elaboration.

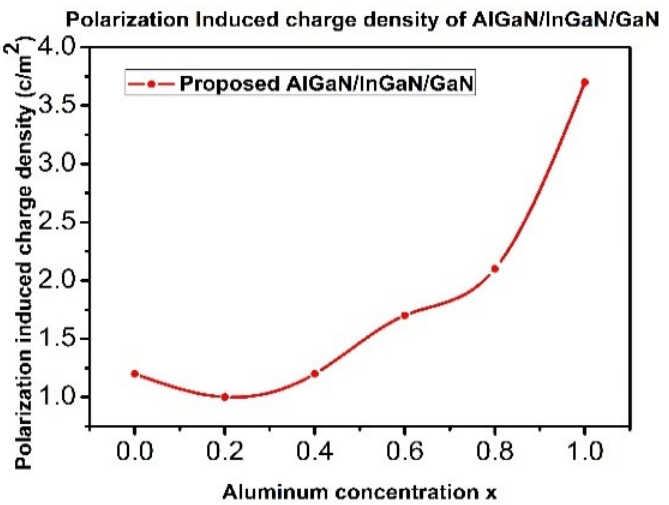

Figure 3. Polarization induced charge density of AIGaN/GaN/InGaN Hetero-structure.

Source: own elaboration.

Polarization charge is calculated in three regions:

- $\quad$ Region a $-0<\mathrm{x}<0.42$

- $\quad$ Region b $-0.43<\mathrm{x}<0.68$

- $\quad$ Region $\mathrm{c}-0.69<\mathrm{x}<1$

where $\mathrm{x}$ is the $\mathrm{Al}$ concentration for $\mathrm{Al}_{\mathrm{x}} \mathrm{Gal}_{-\mathrm{x}} \mathrm{N}$ structure.

The variation happening in sheet charge is observed in the region $\mathrm{I}$ i.e. $\mathrm{x}$ varies from 0 to 0.4 as shown in Figure 5. In this region the sheet charge of $\mathrm{AlGaN} / \mathrm{GaN} / \mathrm{InGaN}$ is about 
$3.75 \times 10^{13} \mathrm{~cm}^{-2}$ whereas in $\mathrm{AlGaN} / \mathrm{GaN}$ it is about $1.7 \times 10^{13} \mathrm{~cm}^{-2}$. In region II only slight variation is observed. And in region III, it is similar to $\mathrm{AlGaN} / \mathrm{GaN}$ HEMT.

\subsection{SIMULATION RESULT OF SHEET CARRIER CONCENTRATION}

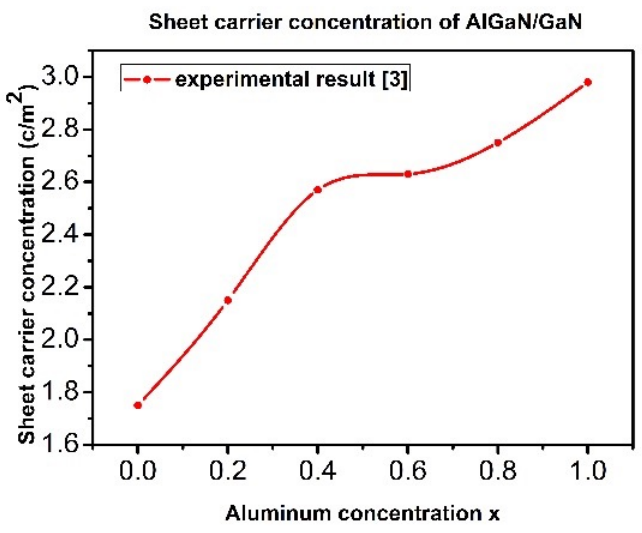

Figure 4. Sheet carrier concentration of AIGaN/GaN Hetero-structure.

Source: own elaboration.

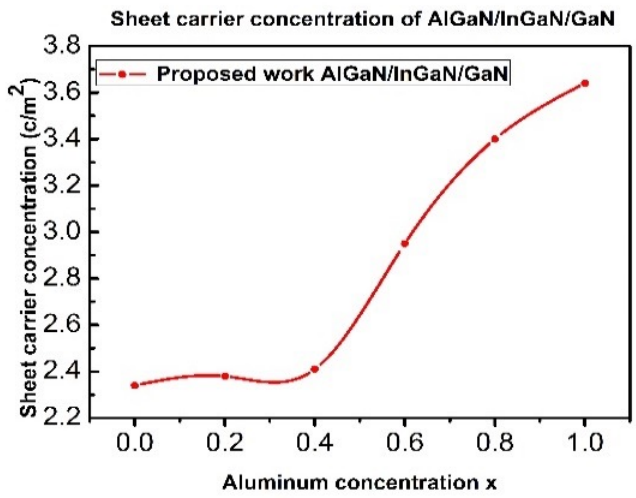

Figure 5. Sheet carrier concentration of $\mathrm{AlGaN} / \mathrm{GaN} / \mathrm{InGaN}$ Hetero-structure.

Source: own elaboration.

The above-mentioned outcomes display the Aluminum concentration $\mathrm{x}$ to the electron concentration $\mathrm{n}_{\mathrm{s}}$. The increase in sheet carrier concentration with increase in $\mathrm{Al}$ concentration in examined. The maximum carrier concentration observed is $3.7 \times 10^{13} \mathrm{~cm}^{-2}$. 
The addition of an InGaN layer has more effect on the increase in carrier concentration than it has on the conventional $\mathrm{AlGaN} / \mathrm{GaN}$ HEMT. The maximum value of carrier concentration in $\mathrm{AlGaN} / \mathrm{GaN} / \mathrm{InGaN}$ exceeds the already existing structure of $\mathrm{AlGaN} /$ GaN at about $3 \times 10^{13} \mathrm{~cm}^{-2}$. The above results display better polarization induced charge densities and sheet carrier concentrations for the proposed AlGaN/GaN/InGaN and hence could be analyzed that it has a better mobility at the 2DEG region and has better current flowing through the region, making it even better and suitable for high frequency applications like RF, space and radiations.

\section{CONCLUSIONS}

In conclusion, compared the sheet charges induced due to polarization effect has been compared which is bound at the interface of $\mathrm{AlGaN} / \mathrm{GaN} / \mathrm{InGaN}$ by varying the value of Aluminum concentration from 0 to 1 . The variation in the aluminum concentraion and piezoelectric constant was observed by considering the strain in the hetero-junction. The nonlinear effect which is arising due to the strain in the piezoelectric polarization is neglected. The sheet carrier concentration in 2DEG is increased by adding the InGaN layer. The two-dimensional electron gas region increases with increase in electron concentration at that area. The sheet carrier concentration and charge densities are improved when taken in comparison with the existing $\mathrm{AlGaN} / \mathrm{GaN}$ hetero-structure.

\section{ACKNOWLEDGEMENT}

The Authors are thankful to the management of Kalasalingam Academy of Research and Education (KARE) for the provision of TCAD laboratory facilities during this research.

\section{REFERENCES}

Ambacher, O., Foutz, B., Smart,J., Shealy,J. R., Weimann, N. G., Chu, K., Murphy, M., Sierakowski, A.J., Schaff, W.J., Eastman, L.F., Dimitrov, R., Mitchell, A., \& Stutzmann, M. (2000). Two dimensional electron gases induced by spontaneous and piezoelectric polarization in undoped and doped $\mathrm{AlGaN} / \mathrm{GaN}$ heterostructures. Journal of applied physics, 87(1), 334-344. https://doi.org/10.1063/1.371866 
Ambacher, O., Smart, J., Shealy, J. R., Weimann, N. G., Chu, K., Murphy, M., Schaff, W.J., Eastman, L.F., Dimitrov, R., Wittmer, L., Stutzmann, M., Rieger, W., \& Hilsenbeck, J. (1999). Two-dimensional electron gases induced by spontaneous and piezoelectric polarization charges in N-and Ga-face AlGaN/ GaN heterostructures. Fournal of applied physics, 85(6), 3222-3233. https://doi. org/10.1063/1.369664

Baskaran, S., Mohanbabu, A., Anbuselvan, N., Mohankumar, N., Godwinraj, D., \& Sarkar, C. K. (2013). Modeling of 2DEG sheet carrier density and DG characteristics in spacer based AlGaN/AIN/GaN HEMT devices. Superlattices and Microstructures, 64, 470-482. https://doi.org/10.1016/j.spmi.2013.10.019

Bernardini, F., Fiorentini, V., \& Vanderbilt, D. (1997). Spontaneous polarization and piezoelectric constants of III-V nitrides. Physical Review B, 56(16), R10024. https:// doi.org/10.1103/PhysRevB.56.R10024

Fletcher, A. A., \& Nirmal, D. (2017). A survey of Gallium Nitride HEMT for RF and high power applications. Superlattices and Microstructures, 109, 519-537. https://doi. org/10.1016/j.spmi.2017.05.042

Foutz, B. E., Ambacher, O., Murphy, M. J., Tilak, V., \& Eastman, L. F. (1999). Polarization induced charge at heterojunctions of the III-V nitrides and their alloys. Physica status solidi (b), 216(1), 415-418. https://doi.org/10.1002/(SICI)15213951(199911)216:1\%3C415::AID-PSSB415\%3E3.0.CO;2-W/

Kumar, R., Arya, S. K., \& Ahlawat, A. (2013). Analysis of small-signal parameters of 2-D MODFET with polarization effects for microwave applications. International Journal of VLSI Design \& Communication Systems, 4(2), 51. https://doi.org/10.5121/ vlsic. 2013.4205

Kuzmik, J. (2002). InAlN/(In) GaN high electron mobility transistors: some aspects of the quantum well heterostructure proposal. Semiconductor Science and Technology, 17(6), 540. https://doi.org/10.1088/0268-1242/17/6/307 
Liu, J., Zhou, Y., Zhu, J., Lau, K. M., \& Chen, K. J. (2005). AlGaN/GaN/InGaN/ GaN DH-HEMTs with an InGaN notch for enhanced carrier confinement. IEEE Electron Device Letters, 27(1), 10-12. https://doi.org/10.1109/LED.2005.861027

Molnar, M., Donoval, D., Kuzmík,J., Marek,J., Chvála, A., Príbytný, P., Mikolasek, M., Rendek, K., \& Palankovski, V. (2014). Simulation study of interface traps and bulk traps in $\mathrm{n}++\mathrm{GaN} / \mathrm{InAlN} / \mathrm{AlN} / \mathrm{GaN}$ high electron mobility transistors. Applied surface science, 312, 157-161. https://doi.org/10.1016/j.apsusc.2014.04.078

Vetury, R., Zhang, N. Q., Keller, S., \& Mishra, U. K. (2001). The impact of surface states on the $\mathrm{DC}$ and $\mathrm{RF}$ characteristics of $\mathrm{AlGaN} / \mathrm{GaN}$ HFETs. IEEE Transactions on Electron Devices, 48(3), 560-566. https://doi.org/10.1109/16.906451

Yu, E. T., Sullivan, G. J., Asbeck, P. M., Wang, G. D., Qiao, D., \& Lau, S. S. (1997). Measurement of piezoelectrically induced charge in $\mathrm{GaN} / \mathrm{AlGaN}$ heterostructure field-effect transistors. Applied Physics Letters, 71(19), 2794-2796. https://doi. org/10.1063/1.120138 
